\title{
Challenges to decision-making processes in the national HTA agency in Brazil: operational procedures, evidence use and recommendations
}

Tania Yuka Yuba, Hillegonda Maria Dutilh Novaes ${ }^{*}$ and Patrícia Coelho de Soárez

\begin{abstract}
Background: The quality of the evidence used in health technology assessment (HTA) agency reports has been considered essential for decision-making processes and their legitimacy. In Brazil, CONITEC is the agency responsible for defining data mandatory for the submission of proposals for the incorporation of new technologies. The objective of this study was to analyse CONITEC recommendation reports, the type of scientific evidence used in them and their compliance with operational procedures.
\end{abstract}

Methods: This is a descriptive study based on CONITEC official reports from July 2012 through December 2016. Data were collected with a specific extraction form and analysed using descriptive statistics.

Results: We evaluated 199 CONITEC recommendation reports. The annual number of reports increased during the study period. The absolute annual number of new technologies incorporated in $2013(n=24)$ was similar to that observed for $2014(n=24)$ and $2015(n=22)$, decreasing in $2016(n=13)$. The type of technology most frequently evaluated was 'drugs' (68.3\%), followed by 'procedures' (20.1\%). Overall, 117 (58.8\%) reports were internal demands, 75 (37.7\%) were external demands and 7 (3.5\%) were mixed demands. There were differences between internal and external demands in terms of the evidence used in the reports and the decision regarding the recommendation to incorporate the technologies. Among the internal demands, the recommendation to incorporate the new technology was made for $70.9 \%$ of the reports, only $9.6 \%$ of which included full HTAs. Among the external demands, the incorporation of the new technology was recommended for $17.3 \%$ of the reports, $76.9 \%$ of which included full HTAs. Of the 101 reports in which incorporation of the new technology was recommended, 88 (87.1\%) did not include a full health economic evaluation and ICER calculation. There are compliance difficulties with the recommendations in the CONITEC internal regulations regarding the type and quality of evidence considered in the analysis of recommendation reports.

Conclusions: The characteristics of the evidence used in recommendation reports and those considered to be mandatory were very different, indicating problems in decision-making processes. There is a need to study, with a broader perspective, the factors that influence the type of evidence used in decision-making processes in order to contribute to the development of better practices and policies.

Keywords: health technology assessment, health policy, evidence-based policy, evidence-based decisions

\footnotetext{
* Correspondence: hidutilh@usp.br

Department of Preventive Medicine, University of São Paulo School of

Medicine, Av. Dr. Arnaldo, 455, Cerqueira César, São Paulo, SP CEP: 01246903,

Brazil
}

(c) The Author(s). 2018 Open Access This article is distributed under the terms of the Creative Commons Attribution 4.0 International License (http://creativecommons.org/licenses/by/4.0/), which permits unrestricted use, distribution, and reproduction in any medium, provided you give appropriate credit to the original author(s) and the source, provide a link to the Creative Commons license, and indicate if changes were made. The Creative Commons Public Domain Dedication waiver (http://creativecommons.org/publicdomain/zero/1.0/) applies to the data made available in this article, unless otherwise stated. 


\section{Background}

Health technology assessment (HTA), a recognised scientific and technological practice, is based on a conceptual framework, uses validated methodologies, is a research topic of interest for academic institutions/research funding agencies, and has social legitimacy. Essentially, HTA proposes the production of knowledge with the potential to contribute explicitly to actions that can positively impact healthcare systems and the health of the population [1-5].

In Brazil, HTA institutionalisation occurred through the creation of structures linked to the Brazilian Sistema Único de Saúde (SUS, Unified Healthcare System) [6]. In 2011, the Comissão Nacional de Incorporação de Tecnologias no SUS (CONITEC, National Committee for Health Technology Incorporation) was created, with the objective of advising the Ministry of Health $(\mathrm{MoH})$ on policies regarding the incorporation of technologies. The CONITEC internal regulations, established through an ordinance enacted in 2012, state that data related to efficacy, effectiveness, accuracy and safety have to be considered in the proposals submitted demanding the incorporation of new technologies, and that scientific data must be obtained by systematic reviews or other means of scientific knowledge synthesis methodologies, and in accordance with national guidelines for health economic evaluations (HEEs) and budget impact analysis [7, 8]. The CONITEC reports must necessarily take into account the costs and benefits of new technologies compared to those already in use in SUS. As part of a HEE, authors are required to present the incremental cost-effectiveness ratio (ICER) of the technology for comparison with a cost-effectiveness threshold (CET) used in the decision. With the inclusion of HEEs as part of the evidence to be considered, the CONITEC internal regulations follow the recommendations of most HTA agencies in developed countries, in particular the United Kingdom's National Institute for Health and Clinical Excellence (NICE) [9].

The CONITEC internal regulations also state that additional information should be considered in the preparation of reports, such as the relevance of the technology for SUS health policy priorities, the viability and sustainability of its incorporation into the public health system, the contributions received in the consultations and public hearings, and the degree of innovation and contribution to the technological development of Brazil. The information to be included in the report must be discussed in a session of the Plenary Committee, with the deliberation on the nature of the recommendation in the report being addressed to the Secretary of Science and Technology of the MoH $[7,8]$.

From an organisational and political point of view, the implementation of CONITEC has shown ongoing development. Its growing technical and political recognition can be measured by the increase in the number of evaluations, the clearer definition of submission and analysis requirements, and the expansion of the committee responsible for the analysis of reports and decision on recommendation. However, certain difficulties have been recognised, such as limited support for the technical staff activities and lack of full transparency in the decision-making processes $[10,11]$.

The purpose of this study was to analyse the type of scientific information used and the compliance with the operational procedures in the CONITEC recommendation reports. To that end, we characterised the type of technology, the sector demanding incorporation, type of evidence, and the extent to which HEE is used in CONITEC recommendations for incorporation into the SUS.

\section{Methods}

This is a descriptive study based on freely accessible CONITEC official reports published between July 2012 and December 2016. A specific data extraction form was created in order to collect information from each of the reports analysed. The reports were classified according to the type of technology, demanding sector, type of HTA, economic evaluation and ICER calculations/CET comparisons.

The demanding sectors were classified into three groups as internal (the public health sector, the judiciary or other public agents), external (the pharmaceutical industry, civil society, medical equipment companies or the food industry), and mixed (the public health sector and the pharmaceutical industry or civil society).

As detailed in Table 1, the types of studies classified as evidence in the reports were divided into four categories according to the eight criteria of the classification system devised by Merlin et al. [12], namely as full HTA, mini-HTA, rapid review and 'other'. The minimum criteria of each study were chosen to allow the classification of the reports analysed. A study was classified as a full HTA if it met at least criteria 1, 2, 3, 4 and 6 of the eight Merlin et al. [12] criteria; as a mini-HTA if it met at least criteria 1, 2, 4 and 6; as a rapid review if it met at least criteria 1,2 and 6; and as 'other' if it did not fit into any of the three preceding categories.

For the characterisation of the types of HEEs presented in the CONITEC recommendation reports, we employed the classification system devised by Drummond et al. [13], which classifies HEEs as full (cost-effectiveness analysis, cost-utility analysis, cost-benefit analysis or costminimisation analysis) or partial (cost description or cost analysis). Budget impact analysis studies were classified as partial economic evaluations.

For the reports that presented a full HEE and ICER, the values were compared with two different concepts of CET:

- The CET adopted by WHO, based on the willingness to pay, suggesting that technologies with ICERs $<1$ gross domestic product (GDP) per capita would be highly cost-effective, that those with ICERs 
Table 1 Classification of studies used as evidence in HTA reports according to selected criteria ${ }^{a}$

\begin{tabular}{|c|c|c|c|c|c|c|c|c|}
\hline \multirow{3}{*}{$\begin{array}{l}\text { Study } \\
\text { category }\end{array}$} & \multicolumn{8}{|l|}{ Criteria } \\
\hline & 1 & 2 & 3 & 4 & 5 & 6 & 7 & 8 \\
\hline & $\begin{array}{l}\text { Description of the } \\
\text { characteristics and } \\
\text { current uses of the } \\
\text { technology }\end{array}$ & $\begin{array}{l}\text { Evaluation of } \\
\text { safety and } \\
\text { effectiveness }\end{array}$ & $\begin{array}{l}\text { Cost- } \\
\text { effectiveness } \\
\text { analysis }\end{array}$ & $\begin{array}{l}\text { Information } \\
\text { on costs and } \\
\text { financial impact }\end{array}$ & $\begin{array}{l}\text { Organisational } \\
\text { considerations }\end{array}$ & $\begin{array}{l}\text { Systematic or } \\
\text { systematised } \\
\text { review }\end{array}$ & $\begin{array}{l}\text { Critical evaluation } \\
\text { of the quality of } \\
\text { the evidence }\end{array}$ & $\begin{array}{l}\text { Ethical, social and } \\
\text { legal consideration }\end{array}$ \\
\hline Full HTA & Always & Always & Always & Always & Optional & Always & Optional & Optional \\
\hline Mini-HTA & Always & Always & $\begin{array}{l}\text { Not } \\
\text { performed }\end{array}$ & Always & Optional & Always & Optional & Optional \\
\hline $\begin{array}{l}\text { Rapid } \\
\text { review }\end{array}$ & Always & Always & $\begin{array}{l}\text { Not } \\
\text { performed }\end{array}$ & Optional & Optional & Always & Optional & Optional \\
\hline Other & Always & Optional & $\begin{array}{l}\text { Not } \\
\text { performed }\end{array}$ & Optional & Optional & Optional & Optional & Optional \\
\hline
\end{tabular}

HTA health technology assessment

${ }^{\mathrm{a}}$ Based on the classification system devised by Merlin et al. [7]

of 1-3 GDP per capita would be cost-effective, and that those with ICERs $>3$ GDP per capita would not be cost-effective.

- The CET adopted by the University of York Centre for Health Economics, based on the opportunity cost, suggesting that the cost-effective range for Brazil would be US\$ 3,210-10,122, which, adjusted by the purchasing power parity established by the World Bank, would, in Brazilian reals ( $\mathrm{R} \$$ ), be equivalent to $\mathrm{R} \$ 5,424.90-17,106.18$.

For that comparison, all of the ICERs presented in the reports were adjusted to 2016 Brazilian reals, on the basis of the extended consumer price index established by the Brazilian Institute of Geography and Statistics [14]. Data were analysed using descriptive statistics.

\section{Results}

Characteristics of the CONITEC recommendation reports CONITEC analysed 541 requests during the period under review (2012-2016). However, we evaluated only the requests that resulted in CONITEC recommendation reports $(n=199)$. Requests that were cancelled for non-compliance with the documentation or at the behest of the requesting party were excluded, as were those that were still under consideration at the end of the study period.

As shown in Fig. 1, the annual number of reports increased over the course of the study period, peaking in $2013(n=54)$. However, the absolute annual number of new technologies recommended to be incorporated in $2013(n=24)$ was similar to that observed for $2014(n=24)$ and $2015(n=22)$, and decreased in $2016(n=13)$. Consequently, the proportion of not recommended technologies

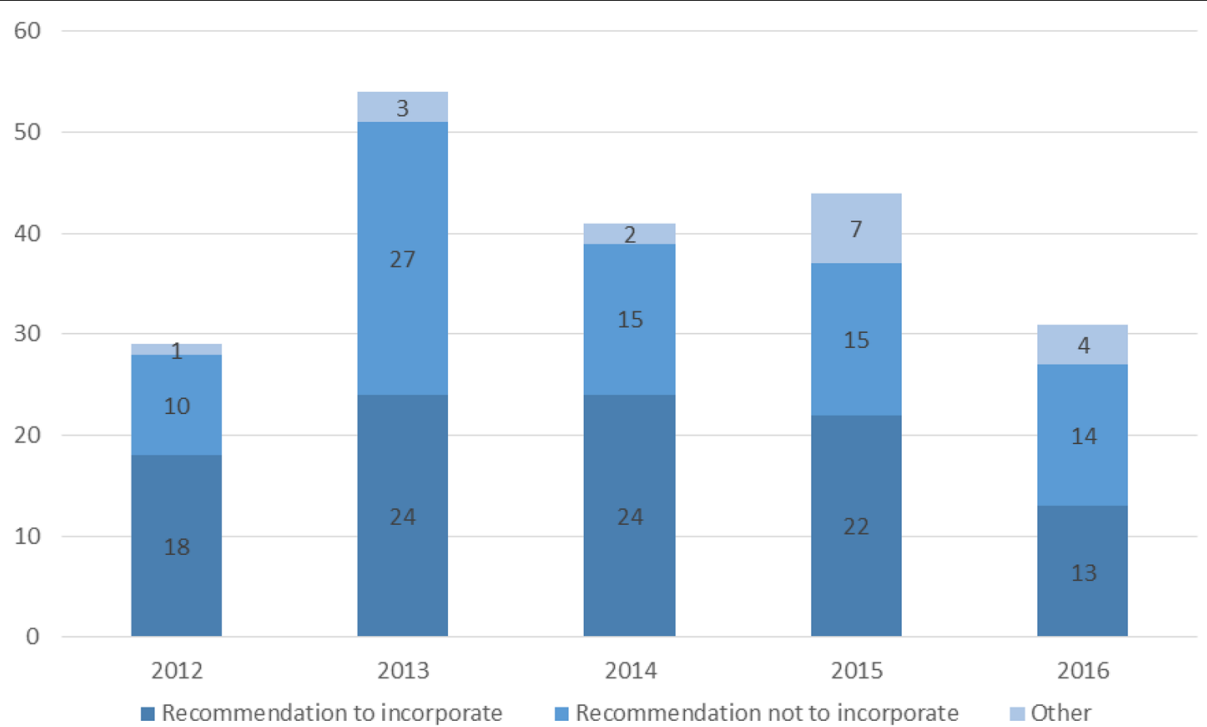

Fig. 1 CONITEC reports according to type of recommendation, 2012-2016 ( $n=199)$. CONITEC: (Brazilian) Comissão Nacional de Incorporação de Tecnologias no Sistema Único de Saúde (CONITEC, National Committee for Health Technology Incorporation); Other: reports recommending broader use or exclusion of the technologies 
was higher in 2013 than in 2014, 2015 and 2016 (50.0\% vs. $36.6 \%, 34.1 \%$ and $45.2 \%$, respectively).

Throughout the study period, the type of technology most frequently evaluated in the reports was 'drugs' (68. $3 \%)$, followed by 'procedures' (20.1\%). The categories 'devices', 'dietary supplements' and 'vaccines' accounted each for only a small (11.5\%) share (Table 2 ). The technologies evaluated in the reports $(n=199)$ were mainly related to the group of diseases in Chapter I of the ICD10 (certain infectious and parasitic diseases; 15.1\%, 30/ 199), followed by Chapter II (neoplasms; 15.1\%, 30/199), Chapter X (diseases of the respiratory system; 10.6\%, 21/ 199) and Chapter XIII (diseases of the musculoskeletal system and connective tissue; 10.1\%, 20/199) (Table 3).

Among the most frequently evaluated, HEEs were mostly conducted in Chapter X (diseases of the respiratory system; 57.1\%, 12/21), Chapter II (neoplasms; 53.3\%, 16/30) and Chapter XIII (diseases of the musculoskeletal system and connective tissue; $45 \%, 9 / 20$ ). There was a balance between reports that presented an HEE and reports without an HEE, except in Chapter I of the ICD-10 (certain infectious and parasitic diseases), where $83.3 \%$ (25/30) of the recommendation reports did not present an HEE.

Of the 199 reports evaluated, 117 (58.8\%) were internal demands, whereas only 75 (37.7\%) were external demands. In the first 2 years (2012 and 2013), external demands outnumbered internal demands, with a reversion in 2014 and
2015 , with 34 (82.9\%) internal demands out of the 41 demands considered in 2014. In 2016, external demands surpassed internal demands. Among the internal demands, the leading type of demanding party was the public health sector, with the pharmaceutical industry leading the external demands. Figure 1 shows the temporal distribution of the CONITEC reports, according to the recommendation to incorporate or not. In 2012 and 2014, the recommendation was for incorporation in the majority of the reports, although there were no temporal trends in the decisions.

Table 4 shows the main characteristics of the CONITEC recommendation reports, namely the type of evidence, demand, HEE and decision regarding the recommendation to incorporate. Concerning the type of study, $82(41.2 \%)$ of the 199 reports were classified as 'other' because they did not meet the criteria to be classified as full HTAs, mini-HTAs or rapid reviews. Of those 82 reports, 64 (78\%) only met the 'description of the characteristics and current uses of the technology' criterion alone or in combination with the 'information on costs and financial impact' criterion. Full HTAs accounted for $78(39.2 \%)$ of the 199 reports, whereas mini-HTAs accounted for $28(14.1 \%)$ and rapid reviews for 11 (5.5\%). Of the 199 recommendation reports, 120 (60.3\%) presented a systematised or systematic review, and 38 (31.7\%) applied a tool for critical evaluation of the quality of the evidence. After 2014, there was an

Table 2 CONITEC reports, by type of technology and type of demand, 2012-2016 $(n=199)$

\begin{tabular}{|c|c|c|c|c|c|c|c|c|c|c|c|c|}
\hline \multirow[t]{2}{*}{ Variable } & \multicolumn{2}{|c|}{2012} & \multicolumn{2}{|c|}{2013} & \multicolumn{2}{|c|}{2014} & \multicolumn{2}{|c|}{2015} & \multicolumn{2}{|c|}{2016} & \multicolumn{2}{|c|}{ Total } \\
\hline & $n$ & $\%$ & $n$ & $\%$ & $n$ & $\%$ & $n$ & $\%$ & $n$ & $\%$ & $n$ & $\%$ \\
\hline \multicolumn{13}{|l|}{ Type of technology } \\
\hline Drugs & 22 & 75.9 & 39 & 72.2 & 18 & 43.9 & 33 & 75.0 & 24 & 77.4 & 136 & 68.3 \\
\hline Procedures & 4 & 13.8 & 7 & 13.0 & 14 & 34.1 & 9 & 20.5 & 6 & 19.4 & 40 & 20.1 \\
\hline Devices & 1 & 3.4 & 4 & 7.4 & 7 & 17.1 & 2 & 4.5 & 0 & - & 14 & 7.0 \\
\hline Dietary supplements & 1 & 3.4 & - & - & 2 & 4.9 & - & - & 1 & 3.2 & 4 & 2.0 \\
\hline Vaccines & 1 & 3.4 & 4 & 7.4 & - & - & - & - & 0 & - & 5 & 2.5 \\
\hline \multicolumn{13}{|l|}{ Type of demand } \\
\hline Internal & 14 & 48.3 & 25 & 46.3 & 34 & 82.9 & 30 & 68.2 & 14 & 45.2 & 117 & 58.8 \\
\hline Public health sector & 13 & 44.8 & 23 & 42.6 & 32 & 78.0 & 29 & 65.9 & 13 & 41.9 & 110 & 55.3 \\
\hline Judiciary and public ministry & 1 & 3.4 & 2 & 3.7 & 2 & 4.9 & 1 & 2.3 & 1 & 3.2 & 7 & 3.5 \\
\hline External & 11 & 37.9 & 28 & 51.9 & 7 & 17.1 & 13 & 29.5 & 16 & 51.6 & 75 & 37.7 \\
\hline Pharmaceutical industry & 11 & 37.9 & 28 & 51.9 & 4 & 9.8 & 12 & 27.3 & 9 & 29 & 64 & 32.2 \\
\hline Civil society & - & - & - & - & 2 & 4.9 & - & - & 4 & 12.9 & 6 & 3.0 \\
\hline Medical device companies & - & - & - & - & - & - & 1 & 2.3 & 2 & 6.4 & 3 & 1.5 \\
\hline Food industry & - & - & - & - & 1 & 2.4 & - & - & 1 & 3.2 & 2 & 1.0 \\
\hline Mixed & 4 & 13.8 & 1 & 1.9 & - & - & 1 & 2.3 & 1 & 3.2 & 7 & 3.5 \\
\hline Public health sector/the pharmaceutical industry or civil society & 4 & 13.8 & 1 & 1.9 & - & - & 1 & 2.3 & 1 & 3.2 & 7 & 3.5 \\
\hline TOTAL & 29 & 100.0 & 54 & 100.0 & 41 & 100.0 & 44 & 100.0 & 31 & 100.0 & 199 & 100.0 \\
\hline
\end{tabular}


Table 3 CONITEC reports, by ICD-10 chapters and use of health economic evaluation, 2012-2016 $(n=199)$

\begin{tabular}{|c|c|c|c|c|}
\hline ICD-10 chapter & Without HEE & With HEE & Total & Percent \\
\hline I Certain infectious and parasitic diseases & 25 & 5 & 30 & $15.1 \%$ \\
\hline II Neoplasms & 14 & 16 & 30 & $15.1 \%$ \\
\hline X Diseases of the respiratory system & 9 & 12 & 21 & $10.6 \%$ \\
\hline XIII Diseases of the musculoskeletal system and connective tissue & 11 & 9 & 20 & $10.1 \%$ \\
\hline IX Diseases of the circulatory system & 2 & 10 & 12 & $6.0 \%$ \\
\hline IV Endocrine, nutritional and metabolic diseases & 9 & 2 & 11 & $5.5 \%$ \\
\hline XI Diseases of the digestive system & 8 & 3 & 11 & $5.5 \%$ \\
\hline $\begin{array}{l}\text { III Diseases of the blood and blood-forming organs and certain } \\
\text { disorders involving the immune mechanism }\end{array}$ & 8 & 2 & 10 & $5.0 \%$ \\
\hline XIV Diseases of the genitourinary system & 5 & 5 & 10 & $5.0 \%$ \\
\hline XXI Factors influencing health status and contact with health services & 7 & 2 & 9 & $4.5 \%$ \\
\hline V Mental and behavioural disorders & 6 & 2 & 8 & $4.0 \%$ \\
\hline VI Diseases of the nervous system & 3 & 4 & 7 & $3.5 \%$ \\
\hline XII Diseases of the skin and subcutaneous tissue & 5 & 1 & 6 & $3.0 \%$ \\
\hline VII Diseases of the eye and adnexa & 2 & 2 & 4 & $2.0 \%$ \\
\hline XVII Congenital malformations, deformations and chromosomal abnormalities & 2 & 1 & 3 & $1.5 \%$ \\
\hline VIII Diseases of the ear and mastoid process & 2 & & 2 & $1.0 \%$ \\
\hline $\mathrm{XVI}$ Certain conditions originating in the perinatal period & 1 & 1 & 2 & $1.0 \%$ \\
\hline XIX Injury, poisoning and certain other consequences of external causes & 1 & 1 & 2 & $1.0 \%$ \\
\hline XV Pregnancy, childbirth and the puerperium & 1 & & 1 & $0.5 \%$ \\
\hline Total & 121 & 78 & 199 & $100.0 \%$ \\
\hline
\end{tabular}

CONITEC Comissão Nacional de Incorporação de Tecnologias no Sistema Único de Saúde (National Committee for Health Technology Incorporation), ICD-10 International Statistical Classification of Diseases and Related Health Problems 10th Revision, HEE health economic evaluation

Table 4 CONITEC reports, by type of recommendation, type of study, type of demand and type of health economic evaluation, 2012-2016 ( $n=199)$

\begin{tabular}{|c|c|c|c|c|c|c|c|c|c|c|c|c|}
\hline \multirow{2}{*}{$\begin{array}{l}\text { Recommendation, by type of } \\
\text { study }\end{array}$} & \multicolumn{4}{|c|}{ Internal request } & \multicolumn{4}{|c|}{ External request } & \multicolumn{3}{|c|}{ Mixed request } & \multirow[t]{2}{*}{ Total } \\
\hline & Full HEE & $C A / C D$ & $\mathrm{BIA}$ & No HEE & Full HEE & $C A / C D$ & $\mathrm{BIA}$ & No HEE & Full HEE & $\mathrm{BIA}$ & No HEE & \\
\hline Incorporate, $n(\%)$ & $83(70.9)$ & & & & $13(17.3)$ & & & & $5(71.4)$ & & & $101(50.8)$ \\
\hline Full HTA & 8 & - & - & - & 10 & - & - & - & 2 & - & - & 20 \\
\hline Mini-HTA & - & 2 & 9 & - & - & - & 1 & - & - & - & - & 12 \\
\hline Rapid review & - & - & - & 2 & - & - & - & - & - & - & - & 2 \\
\hline Other & - & - & 44 & 18 & - & 1 & 1 & - & - & 2 & 1 & 67 \\
\hline Do not incorporate, $n(\%)$ & $17(14.5)$ & & & & $62(82.7)$ & & & & $2(28.6)$ & & & $81(40.7)$ \\
\hline Full HTA & 2 & - & - & - & 55 & - & - & - & 1 & - & - & 58 \\
\hline Mini-HTA & - & 1 & 9 & - & - & 2 & 3 & - & - & - & - & 15 \\
\hline Rapid review & - & - & - & 5 & - & - & - & 1 & - & - & - & 6 \\
\hline Other & - & - & - & - & - & - & - & 1 & - & - & 1 & 2 \\
\hline Maintain/expand/exclude, $n$ (\%) & $17(14.5)$ & & & & - & & & & - & & & $17(8.5)$ \\
\hline Mini-HTA & - & - & 1 & - & - & - & - & - & - & - & - & 1 \\
\hline Rapid review & - & - & - & 3 & - & - & - & - & - & - & - & 3 \\
\hline Other & - & - & 1 & 12 & - & - & - & - & - & - & - & 13 \\
\hline Total, $n$ (\%) & $117(100.0)$ & & & & 75 (100.0) & & & & 7 (100.0) & & & 199 (100.0) \\
\hline
\end{tabular}

CONITEC Comissão Nacional de Incorporação de Tecnologias no Sistema Único de Saúde (National Committee for Health Technology Incorporation), EE economic evaluation (cost-effectiveness analysis, cost-utility analysis, cost-benefit analysis or cost-minimisation analysis), $C A$ cost analysis, $C D$ cost description, $B I A$ budget impact analysis Includes a BIA 
increase in the percentage of reports that critically evaluated the quality of the evidence, especially in 2015 (42.3\%) and 2016 (60.0\%). The most frequently used tool was the Grading of Recommendations, Assessment, Development and Evaluations (GRADE), with or without another tool $(44.7 \%)$, followed by the Jadad scale (15.8\%), and the Cochrane collaboration tool to assess risk of bias (13.2\%). Of the 199 reports, 78 (39.2\%) included a full HEE.

Among the 117 reports involving internal demands, incorporation of the new technology was recommended in 83 (70.9\%). In comparison, incorporation of the new technology was recommended in only $13(17.3 \%)$ of the 75 reports involving external demands. Of the 83 reports involving internal demands that were recommended, 62 (74.7\%) were classified as 'other', accompanied by the description of the characteristics/current uses of the technology, and included a limited budget impact analysis and no type of economic evaluation. Of the 62 reports involving external demands that were not recommended, 55 (88.7\%) were classified as full HTAs and included a full HEE.

\section{Use of HEEs in the CONITEC reports and decision on incorporation}

Of the 101 reports in which incorporation of the new technology was recommended, 20 (19.8\%) included a full HEE and 13 (12.9\%) included a full HEE with ICER calculation. Therefore, $88(87.1 \%)$ of the reports recommended incorporation without a full HEE and ICER calculation. Of the 13 reports including an ICER calculation, 6 compared their results with the CET adopted by WHO. When comparing the ICER values with the WHO CET, we found that 12 of the 13 technologies addressed in those reports would be cost-effective, all 12 showing an ICER < 3 GDP per capita (i.e. < R 81,687); of these, 5 technologies showed an ICER $\leq 1$ GDP per capita (i.e. R\$ 27,229), indicating that they would be highly cost-effective. When comparing the ICER values with the CET adopted by the Centre for Health Economics, we found that only 3 technologies showed ICERs $<$ R\$ 17,106.18 (the upper limit of the cost-effective range for Brazil) and would therefore be considered cost-effective (Fig. 2).

Of the 81 reports in which incorporation of the new technology was not recommended, 58 (71.6\%) included a full HEE and 45 (55.6\%) included a full HEE with ICER calculation. Of the 45 reports including an ICER calculation, 15 compared their results with the CET adopted by WHO. When comparing the ICER values with the WHO CET, we found that 12 of the 15 technologies addressed in those reports would be cost-effective, showing an ICER < 3 GDP per capita (i.e. $<$ R 81,687 ); of these, 7 technologies showed an ICER $\leq 1$ GDP per capita (i.e. R\$ 27,229), indicating that they would be highly cost-effective. When comparing the ICER values with the CET adopted by the
Centre for Health Economics, we found that 5 technologies showed ICERs $<$ R $\$ 17,106.18$ (the upper limit of the cost-effective range for Brazil) and would therefore be considered cost-effective.

\section{Discussion}

The creation of CONITEC in 2011 represented an important step in the institutionalisation of HTA as a specific policy within the overall health policy of the $\mathrm{MoH}$ and the SUS. The ongoing activity of CONITEC can be seen in the number of reports produced (199 over the 5 years analysed herein), although no parameters have been established in order to define the number needed to meet the needs of the SUS.

Regarding the type of technology analysed in the CONITEC reports, there was a predominance of drugs (68.3\%), as has been the norm for most HTA agencies. Previous studies presented very similar figures of $61.4 \%$ [15] and $62.1 \%$ [16]. In the period under study, there was also a predominance of internal demands for CONITEC to recommend the incorporation of a given technology, and most of those demands originated in the public health sector, whereas most of the external demands came from the pharmaceutical industry. There were large variations in the proportional distribution of those demands over the years. For example, $82.9 \%$ of the reports evaluated in 2014 were generated from internal demands. The significance of such variation remains unclear, and a deeper understanding calls for analyses of the technologies, as well as of their political and economic contexts.

Our findings indicate that there are difficulties related to compliance with the recommendations in the CONITEC internal regulations regarding the type of evidence that should be presented in the recommendation reports. Despite the emphasis that the internal regulations give to economic evaluation as relevant evidence, full HTAs were employed in only $39.2 \%$ of the reports. Reports that included an ICER calculation and used an explicit CET to support the recommendation were rare ( $n=13)$. The current international debate questions the need for countries to adopt explicit thresholds and recent publications from medium- and low-income countries emphasise the interest in developing thresholds that clearly incorporate budget constraints and opportunity costs in these countries [17-19].

Although we applied a number of criteria for the characterisation of study types lower than that suggested in the International Network of Agencies for Health Technology Assessment classification, we found that nearly half of the reports were classified as 'other', as they presented only a description of the characteristics and current uses of the technology, with or without information on its costs and financial impact. 


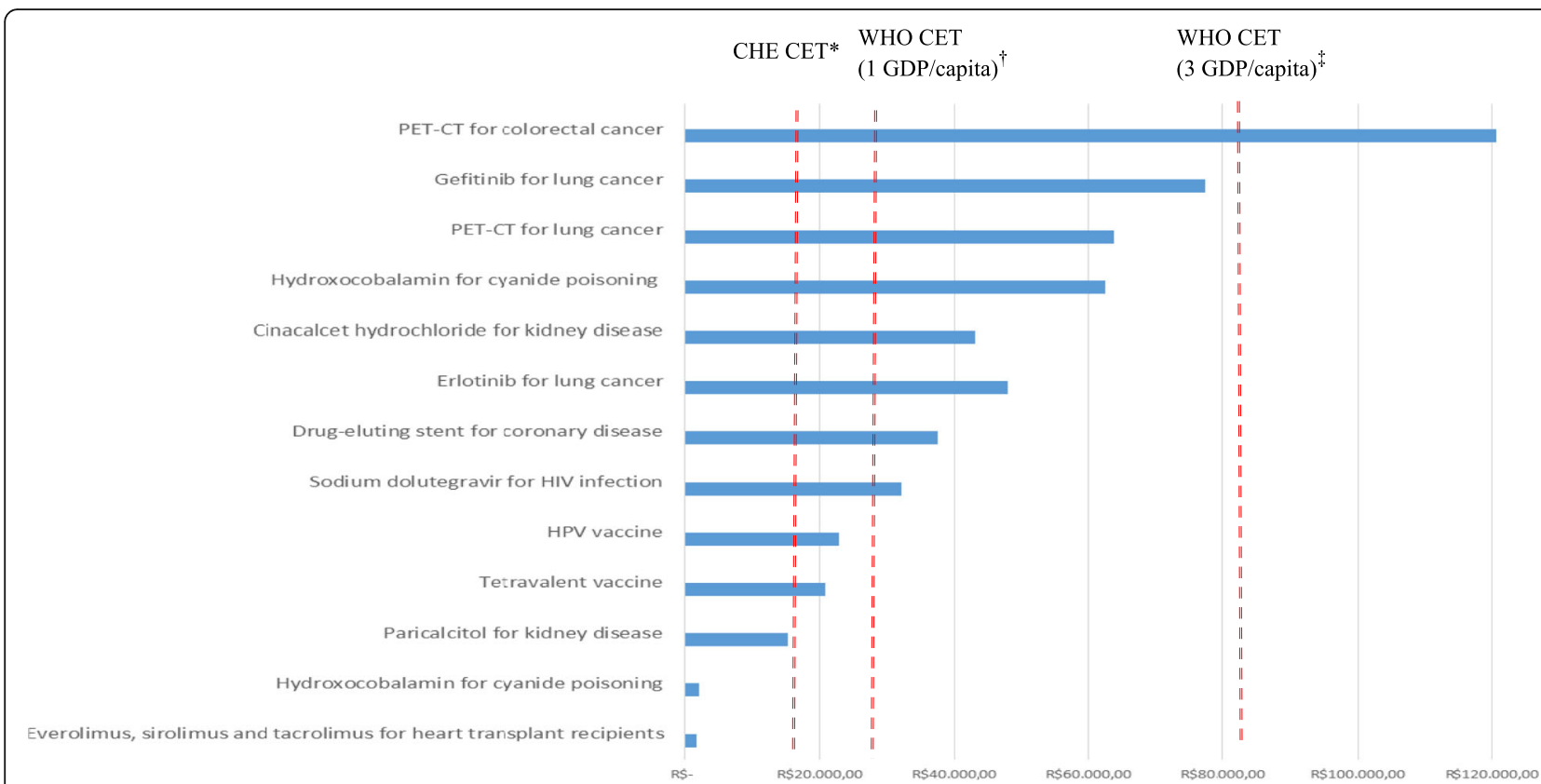

Fig. 2 Incremental cost-effectiveness ratios, in 2016 Brazilian reals (R\$), for the technologies that gained a CONITEC recommendation for incorporation, 2012-2016 ( $n=13$ ). CONITEC Comissão Nacional de Incorporação de Tecnologias no Sistema Único de Saúde (National Commission for the Incorporation of Technologies into the Unified Healthcare System), CHE Centre for Health Economics (University of York), CET cost-effectiveness threshold, WHO World Health Organization, GDP gross domestic product, PET-CT positron emission tomography-computed tomography, HPV human papillomavirus. ${ }^{*} R \$ 17,106.18 .{ }^{\dagger} R \$ 27,229.00 .{ }^{\ddagger} R \$ 81,687.00$

We observed relevant differences between internal and external demands in terms of the evidence used in the reports and the decision regarding the recommendation to incorporate the technology. The higher proportion of recommendations to incorporate among internal demands was also found in a previous study [16]. Among the internal demands, the recommendation to incorporate the new technology was made for $70.9 \%$ of the reports, only $9.6 \%$ of which included full HTAs. Among those for which the recommendation was not to incorporate, $11.8 \%$ included full HTAs. Among the external demands, the incorporation of the new technology was recommended for $17.3 \%$ of the reports, and $76.9 \%$ of those reports included full HTAs, comparable to the 88 . $7 \%$ observed in the reports for which the recommendation was not to incorporate the new technology.

The two most important findings of the present study are the lack of compliance with what is recommended in the CONITEC internal regulations, in terms of the type and quality of evidence considered in the analysis of the demands for incorporation of new technologies, and the clear difference between the evidence considered in internal demands and in external demands.

The literature on the use of evidence in public policy decision-making provides important indications to understanding the results obtained in our study. The most common explanation for the mismatch between the evidence recommended and the evidence effectively used is the limited scientific knowledge in health and shortage of researchers qualified to produce it, especially in middle- and low-income countries, in addition to the lack of dialogue between researchers and policy-makers. Therefore, there is a need for ongoing investment in research, and for the training of qualified researchers and policy-makers, as well as for the promotion of better communication between the parties. Since 2008, there has been a significant increase in the production of literature in the HTA area in Brazil [20], as well as in the development of courses for training in systematic reviews, technical/scientific reports and guideline dissemination in Brazil. However, all of this is quite recent and there is a need for additional, sustained investment in HTA as a knowledge source and health policy [21, 22].

Nevertheless, this perspective alone does not allow a full understanding of the complex nature of the procedures involved in the use of evidence in decision-making processes and policies. To improve such understanding, there is a need to incorporate studies from the social sciences on policy implementation, showing that they are complex processes in which the initial expectations are always transformed by changing socioeconomic and political conditions, health policies and stakeholder positions [23]. The differences between internal and external demands in terms of the use of evidence indicate that other factors are at play in the development of consensus recommendations. Internal demands may have had greater political legitimacy, having already been analysed 
and validated in other sectors of the $\mathrm{MoH}$, stimulating recommendation. It is noteworthy that $\mathrm{MoH}$ ordinance no. 26 , enacted in 2015 , redefining the requirements for submission of requests for CONITEC analysis of new technologies to be incorporated, excluded the need to include economic evaluations in the demands [19]. CONITEC is a very recent HTA body, and has contributed with many advances in technology incorporation, but it is still undergoing a process of implementation, with barriers and constraints dependent on a sustainable and adequate relation with health policies for the SUS as a whole.

\section{Conclusions}

An analysis of the changes that CONITEC underwent in the period under study, in terms of the forms of representation of social interests, their representative dynamics and their relations with the $\mathrm{MoH}$, is necessary in order to understand the differences between the evidence recommended and that used in the reports. The deepening of the understanding of the political and institutional factors that affect the use of evidence in decision-making processes, which are not only technical/administrative but eminently political as well as part of the exercise of a democratic deliberative political practice, may allow the identification of the elements required for analyses that are more comprehensive and complex. Such analyses could contribute to the understanding of past and current contexts, as well as to the development of new practices and policies $[24,25]$.

\section{Abbreviations}

CET: cost-effectiveness threshold; CONITEC: Comissão Nacional de Incorporação de Tecnologias no SUS (National Committee for Health Technology Incorporation); GDP: gross domestic product; HEE: health economic evaluation; HTA: health technology assessment; ICER: incremental cost-effectiveness ratio; MoH: Ministry of Health; SUS: (Brazilian) Sistema Único de Saúde (Unified Healthcare System)

\section{Acknowledgments}

We thank CONITEC for the availability of the Health Technology Reports.

\section{Funding}

No direct funding was received for this study. However, PCS is the recipient of grants from the Fundação de Amparo à Pesquisa do Estado de São Paulo (FAPESP, São Paulo Research Foundation; Research Grant no. 2012/22126-3) and from the Conselho Nacional de Desenvolvimento Cientifico e Tecnológico (CNPq, National Council for Technological and Scientific Development; Research Grant no. 304580/2016-3); HMDN is the recipient of a grant from the CNPq (Research Grant no. 306536/2015-3); and TYY is the recipient of a grant from FAPESP (Research Grant no. 2015/02713-0). PCS, HMDN and TYY are researchers from the IATS, National Institute of Science and Technology for Health Technology Assessment (IATS) - CNPq/Brazil.

\section{Availability of data and materials}

The dataset supporting the conclusions of this article is available on the website of the Department of Preventive Medicine, University of São Paulo School of Medicine (http://www2.fm.usp.br/preventiva/

mostrahp.php?origem=preventiva\&xcod=dep_arquivo\&dequem=P\%E1 ginas) repository (http://www2.fm.usp.br/gdc/docs/

preventiva_302_2012_2016_data_article.xlsx).

\section{Authors' contributions}

TYY, HMDN and PCS conceived the idea of using a performance measurement framework to encourage the translation of effective researchgenerated knowledge. TYY extracted data from the recommendation reports. TYY, HMDN and PCS categorised the reports. All of the authors contributed to the literature search and reviews. All authors helped draft the article, have read the final manuscript, and have approved its submission.

\section{Competing interests}

The authors declare that they have no competing interests.

\section{Publisher's Note}

Springer Nature remains neutral with regard to jurisdictional claims in published maps and institutional affiliations.

Received: 31 August 2017 Accepted: 24 April 2018

Published online: 11 May 2018

\section{References}

1. Novaes H, De Soarez P. Avaliação de tecnologias em saúde: técnicas, práticas e políticas. In: Costa L, Bahia L, Gadelha C, editors. Saúde, Desenvolvimento e Inovação. Rio de Janeiro: Fiocruz; 2015. p. 327-58.

2. Denis $\lrcorner$, Lehoux $P$, Champagne FA. Knowledge utilization perspective on fine-tuning dissemination and contextualizing knowledge. In: LumieuxCharles L, Champagne F, editors. Using Knowledge and Evidence in Health Care. Toronto. Canada: University of Toronto Press; 2008. p. 18-40.

3. Gibbons M, Limoges C, Nowotny H, Schwartzman S, Scott P, Trow M. The New Production of Knowledge: The Dynamics of Science and Research in Contemporary Societies. London: Sage; 1994.

4. Ottoson J. Knowledge-for-action theories in evaluation: Knowledge utilization, diffusion, implementation, transfer, and translation. In: Ottoson JM, Hawe P, editors. Knowledge Utilization, Diffusion, Implementation, Transfer, and Translation: Implications for Evaluation New Directions for Evaluation; 2009. p. 7-20.

5. Gerhardus A, Dorendorf E, Rottingen JA, Santamera AS. What are the effects of HTA reports on the health system? Evidence from the research literature. In: Velasco-Garrido M, Kristensen F, Nielsen C, Busse R, editors. Health Technology Assessment and Health Policy-Making in Europe: Current Status, Challenges and Potential. Brussels: WHO on behalf of the European Observatory on Health System and Policies; 2008.

6. Novaes HM, Soárez PC. Health technology assessment (HTA) organizations: dimensions of the institutional and political framework. Cad Saude Publica. 2016;32(Suppl 2):e00022315.

7. Brasil. Ministério da Saúde. Lei $n^{\circ} 12.401$, de 28 de abril de 2011. Altera a Lei n 8.080, de 19 de setembro de 1990 para dispor sobre a assistência terapêutica e a incorporação de tecnologia em saúde no âmbito do Sistema Único de Saúde. Brasília: Ministério da Saúde; 2011.

8. Brasil. Ministério da Saúde. Decreto n 7.646, de 21 de dezembro de 2011. Regulamenta a Lei $n^{\circ} 12.401$, de 28 de abril de 2011 e Dispõe sobre a Comissão Nacional de Incorporação de Tecnologias no Sistema Único de Saúde e sobre o processo administrativo para incorporação, exclusão e alteração de tecnologias em saúde pelo Sistema Único de Saúde - SUS. Brasília: Ministério da Saúde; 2011.

9. Raftery J, Powell J. Health technology assessment in the UK. Lancet. 2013; 382:1278-85.

10. Wilsdon T, Fiz E, Haderi A. A comparative analysis of the role and impact of Health Technology Assessment: 2013 CRA Project No D19197-00. Washington: CRA. Charles River Associates; 2014. p. 132.

11. Silva HP, Petramale CA, Elias FT. Advances and challenges to the Brazilian policy of health technology management. Rev Saude Publica. 2012;46(Suppl 1):83-90.

12. Merlin T, Tamblyn D, Ellery B, INAHTA Quality Assurance Group. What's in a name? Developing definitions for common health technology assessment product types of the International Network of Agencies for Health Technology Assessment (INAHTA). Int J Technol Assess Health Care. 2014;30(4):430-7.

13. Drummond MF, Sculpher MJ, Claxton K, Stoddart GL, GW T. Methods for the Economic Evaluation of Health Care Programmes. London: Oxford; 2015. p. 464.

14. Banco Central do Brasil. Calculadora do cidadão. Correção de valores. Índices de preços. https://www3.bcb.gov.br/CALCIDADAO/publico/ exibirFormCorrecaoValores.do?.

15. Nunes LMN, Fonteles MMF, Passos ACB, PSD A. Evaluation of demands of inclusion, exclusion and alteration of Technologies in the Brazilian Health 
System submitted to the National Committee on Technology Incorporation. Braz J Pharm Sci. 2017;53:e16073.

16. Caetano R, Silva RMD, Pedro É, Oliveira IAG, Biz AN, Santana P. Incorporation of new medicines by the National Commission for Incorporation of Technologies, 2012 to June 2016. Cien Saude Colet. 2017;22:2513-25.

17. Griffiths UK, Legood R, Pitt C. Comparison of economic evaluation methods across low-income, middle-income and high-income countries: what are the differences and why? Health Econ. 2016;25(Suppl 1):29-41.

18. Pitt C, Vassall A, Teerawattananon Y, Griffiths UK, Guinness L, Walker D, Foster N, Hanson K. Foreword: Health economic evaluations in low- and middle-income countries: methodological issues and challenges for priority setting. Health Econ. 2016;25(Suppl 1):1-5.

19. Soarez PC, Novaes HMD. Cost-effectiveness thresholds and the Brazilian Unified National Health System. Cad Saude Publica. 2017;33:e00040717.

20. Decimoni $T C$, Leandro R, Rozman LM, Craig D, Iglesias CP, Novaes HMD, de Soárez PC. Systematic review of health economic evaluation studies developed in Brazil from 1980 to 2013. Front Public Health. 2018;6:52.

21. Oliver K, Lorenc T, Innvær S. New directions in evidence-based policy research: a critical analysis of the literature. Health Res Policy Syst. 2014;12:34.

22. Cairney P, Oliver K. Evidence-based policymaking is not like evidence-based medicine, so how far should you go to bridge the divide between evidence and policy? Health Res Policy Syst. 2017;15:35.

23. Hupe P. And the rest is implementation.' Comparing approaches to what happens in policy processes beyond Great Expectations. Public Policy Admin. 2016;31:103-21.

24. Liverani M, Hawkins B, Parkhurst JO. Political and institutional influences on the use of evidence in public health policy. A systematic review. PLoS One. 2013;8:e77404.

25. Parkhurst J. The Politics of Evidence: From Evidence-Based Policy to the Good Governance of Evidence. Abingdon, Oxon: Routledge; 2017.

Ready to submit your research? Choose BMC and benefit from:

- fast, convenient online submission

- thorough peer review by experienced researchers in your field

- rapid publication on acceptance

- support for research data, including large and complex data types

- gold Open Access which fosters wider collaboration and increased citations

- maximum visibility for your research: over $100 \mathrm{M}$ website views per year 